Review Article

\title{
A role for adeno-associated viral vectors in gene therapy
}

\author{
Renata dos Santos Coura and Nance Beyer Nardi \\ Laboratório de Imunogenética, Departamento de Genética, Universidade Federal do Rio Grande do Sul, \\ Porto Alegre, RS, Brazil.
}

\begin{abstract}
Gene therapy constitutes a therapeutic intervention based on modification of the genetic material of living cells, by correcting genetic defects or overexpressing therapeutic proteins. The success of gene therapy protocols depends on the availability of therapeutically suitable genes, appropriate gene delivery systems and proof of safety and efficacy. Recent advances on the development of gene delivery systems, particularly on viral vectors engineering and improved gene regulatory systems, have led to marked progress in this field. Although the available vector systems can successfully transfer genes into cells, the ideal delivery vehicle has not been found. In this context, adeno-associated virus vectors (AAV) are arising as a promising tool for a wide range of applications, due to a combination of characteristics such as lack of pathogenicity and immunogenicity, wide range of cell tropism and long-term gene expression. Since its isolation, the biological properties of the adeno-associated virus have been increasingly understood, improving our ability to manipulate and use it as a safe and efficient gene therapy vector of wide spectrum. In this work, we review the bases of gene therapy, main types of gene transfer systems and basic properties and use of AAV vectors.
\end{abstract}

Key words: Adeno-associated virus, AAV-based recombinant vectors, gene therapy.

Received: August 29, 2007; Accepted: November 8, 2007.

\section{Introduction}

Gene therapy is a clinical strategy involving gene transfer with therapeutic purposes. It is based on the concept that an exogenous gene (transgene) is able to modify the biology and phenotype of target cells, tissues and organs. Initially designed to definitely correct monogenic disorders, such as cystic fibrosis, severe combined immunodeficiency or muscular dystrophy, gene therapy has evolved into a promising therapeutic modality for a diverse array of diseases. Targets are expanding and currently include not only genetic, but also many acquired diseases, such as cancer, tissue degeneration or infectious diseases (Worgall, 2005; Zubler, 2006). Depending on the duration planned for the treatment, type and location of target cells, and whether they undergo division or are quiescent, different vectors may be used, involving nonviral methods, nonintegrating viral vectors or integrating viral vectors (reviewed by El-Aneed, 2004; Zubler, 2006).

The first gene therapy clinical trial was carried out in 1989, in patients with advanced melanoma, using tumorinfiltrating lymphocytes modified by retroviral transduc-

Send correspondence to Nance Beyer Nardi. Laboratório de Imunogenética, Departamento de Genética, Universidade Federal do Rio Grande do Sul, Av. Bento Gonçalves 9500, 91501-970 Porto Alegre, RS, Brazil. E-mail: nardi@ufrgs.br. tion (Rosenberg et al., 1990). In the early nineties, a clinical trial with children with severe combined immunodeficiency (SCID) was also performed, by retrovirus transfer of the deaminase adenosine gene to lymphocytes isolated from these patients (Blaese et al., 1995). Since then, more than 5,000 patients have been treated in more than 1,000 clinical protocols all over the world (http://www.wiley.co. uk/genetherapy/clinical). Despite the initial enthusiasm, however, the efficacy of gene therapy in clinical trials has not been as high as expected; a situation further complicated by ethical and safety concerns (Verma and Somia, 1997; Rubanyi, 2001; El-Aneed, 2004; Edelstein et al., 2004; Zubler, 2006). Further studies are being developed to solve these limitations.

\section{Vectors}

The primary challenge in gene therapy is the development of efficient gene delivery vectors to target the selected tissues, where proper gene expression may be achieved. The ideal gene delivery method should be able to protect the transgene against degradation by nucleases, allow transport of the transgene into the nucleus of target cells, and have no potential inflammatory or cytotoxic side effects. However, the choice of the vector, as well as the protocol of treatment and the outcome of the therapy, are 
determined mainly by the nature of the disease and by the target organ (Salani et al., 2005; Gao et al., 2007). Therefore, other important parameters to be considered in the definition of the best type of vector include its purity and titer, efficiency, size limitations for insertion of transgenes, ability to infect dividing and/or quiescent cells, duration of expression of the transgene, integration into the host genome, tropism, and toxicity or immunogenicity of the vector (Goverdhana et al., 2005).

The introduction of therapeutic genes into target cells, leading to efficient and stable expression of the transgene with minimal adverse effects, can be achieved using viral and nonviral vectors. Viral vectors can mediate gene transfer with high efficiency and the possibility of longterm gene expression, since they can easily enter cells and deliver their genetic material into the nucleus; therefore, they are in most cases more efficient than nonviral delivery systems. However, the risks of immunogenicity and insertion mutagenesis, disclosed in gene therapy clinical trials, pose serious safety concerns about some commonly used viral vectors. Limitations in the size of the transgene that recombinant viruses can carry and issues related to the production of viral vectors present additional practical challenges.

In trying to bypass safety issues intrinsic to the use of viral vectors, several nonviral vectors are being developed (Goverdhana et al., 2005). Although significant progress has been made in studies on the basic biology and applications of various nonviral gene delivery systems, most of them are still much less efficient than viral vectors, particularly for in vivo gene delivery (Gao et al., 2007).

\section{Non-viral systems}

The underlying principle of nonviral vector systems is to complex the DNA vector with molecules that will facilitate DNA entry into the cells of interest. Complexed DNA binds to the cell membrane, triggering either nonspecific or receptor-mediated endocytosis. Upon entry into the cell, these complexes remain in endosomes, and their ability to escape before lysosomal enzymes destroy them is an essential characteristic of a successful nonviral vector.
Once released from the endosomes, these complexes must enter the nucleus and complexed DNA must be released from its carrier molecules and adequately transcribed.

Methods of nonviral gene delivery have been explored using physical (carrier-free gene delivery) and chemical approaches (synthetic vector-based gene delivery). Physical approaches, including needle injection, electroporation, gene gun, ultrasound, and hydrodynamic delivery, employ a force that permeates the cell membrane and facilitates intracellular gene transfer (Table 1). Chemical approaches use synthetic or naturally occurring compounds as carriers to deliver the transgene into cells (Table 2).

\section{Viral systems}

For the production of efficient and safe viral vectors, essential sequences for viral particle assembly, genome package, and transgene delivery to target cells must be identified. Dispensable genes are then deleted from the viral genome in order to reduce its pathogenicity and immunogenicity and, finally, the transgene is integrated into the construct. Some viral vectors are able to integrate into the host genome, whereas others remain episomal. Integrating viruses result in persistent transgene expression. Non-integrating vectors, such as adenoviruses whose viral DNA is maintained in episomal form in infected cells, lead to transient transgene expression. Each type of vector presents specific advantages and limitations that make them appropriate for particular applications (Pfeifer and Verma, 2001). Most of the vectors currently used for gene transfer are derived from human pathogens, from which essential viral genes have been deleted to make them nonpathogenic. They usually have a broad tropism, so that different types of cells and/or tissues may be targeted.

The ideal vector has not been described yet, but its characteristics should include:

- easy and efficient production of high titers of the viral particle;

- absence of toxicity for target cells and undesirable effects such as immune response against the vector or the transgene;

Table 1 - Physical methods of gene therapy with non-viral vectors.

\begin{tabular}{|c|c|c|c|}
\hline Method & Description & Advantages & Limitations \\
\hline Microinjection & Direct injection of plasmidial DNA into target cell & $\begin{array}{l}\text { Small amount of DNA required for } \\
\text { transference }\end{array}$ & $\begin{array}{l}\text { Extremely difficult, low perfor- } \\
\text { mance }\end{array}$ \\
\hline Electroporation & $\begin{array}{l}\text { Plasmidial DNA administration through applica- } \\
\text { tion of an alternate electric field that breaks the } \\
\text { membrane forming transient pores through of } \\
\text { which DNA complexes can cross }\end{array}$ & $\begin{array}{l}\text { High levels of transgene expression } \\
\text { in several organs }\end{array}$ & $\begin{array}{l}\text { Can cause local tissue damage and } \\
\text { inflammation; depend on high } \\
\text { plasmidial DNA concentrations }\end{array}$ \\
\hline Biobalistic & $\begin{array}{l}\text { Acceleration system by a carrier gas that projects } \\
\text { the DNA molecule associated with microparticles } \\
\text { of tungsten or gold, into target cells, promoting the } \\
\text { intracellular expression of the exogen DNA }\end{array}$ & $\begin{array}{l}\text { Allows transfection of complexes } \\
\text { genes; absence of toxicity; efficacy } \\
\text { of in vitro transfection relatively } \\
\text { high }\end{array}$ & $\begin{array}{l}\text { Use limited to superficial tissues } \\
\text { and organs, as the muscle; shows } \\
\text { limitations for the use in vivo }\end{array}$ \\
\hline
\end{tabular}


Table 2 - Chemical methods of gene therapy with non-viral vectors.

\begin{tabular}{|c|c|c|c|}
\hline Method & Description & Advantages & Limitations \\
\hline Nude DNA & $\begin{array}{l}\text { Direct injection of plasmidial DNA into } \\
\text { target cell (non-complexed to any particle) }\end{array}$ & $\begin{array}{l}\text { Successful transgene expression } \\
(1 \%-40 \%) \text { transferred through nude DNA } \\
\text { hidrodynamically* injected in mice }\end{array}$ & $\begin{array}{l}\text { Fast degradation and neutralization by en- } \\
\text { dogenous DNAses; limited potential of } \\
\text { electrostatic interactions with anionic } \\
\text { lipids of the cellular membrane (negative } \\
\text { charge of DNA molecule); uncertain clini- } \\
\text { cal applicability and problems for } \\
\text { large-scale use }\end{array}$ \\
\hline Lipoplexes & $\begin{array}{l}\text { Cationic lipids complexed to DNA that } \\
\text { neutralize its electrostatic charge, allowing } \\
\text { DNA-cellular membrane interaction, and } \\
\text { thus, increasing the transfection efficacy }\end{array}$ & $\begin{array}{l}\text { Lipoplexes are powerful systems to intro- } \\
\text { duce plasmids into target cells; high level } \\
\text { transgene expression after direct adminis- } \\
\text { tration or injection in target tissues }\end{array}$ & $\begin{array}{l}\text { Interaction with plasmatic proteins and } \\
\text { other extracellular proteins that can inacti- } \\
\text { vate them due to their hydrophobic and } \\
\text { cationic surface; indiscriminate transgene } \\
\text { expression in cells at the administration } \\
\text { site (non-specific membrane activity); low } \\
\text { efficacy of quiescent cells transfection }\end{array}$ \\
\hline
\end{tabular}

*fast intravenous administration of a great volume (up to $\sim 2.5 \mathrm{~mL}$ in mice).

- capacity of site-specific integration, allowing longterm transgene expression, for treating diseases such as genetic disorders;

- capacity of transduction of specific cell types;

- infection of proliferative and quiescent cells.

The most commonly used viral vectors for gene therapy are based on adenoviruses (Ad), adeno-associated viruses (AAV) and retrovirus/lentivirus vectors. Their main characteristics are summarized in Table 3.

\section{Adeno-associated viruses - structure and life cycle}

Adeno-associated viruses (AAV) are non-pathogenic parvoviruses. The Parvoviridae family includes small, icosahedral and non-enveloped viruses whose genome is a single stranded DNA. AAV is one of the smallest viruses, with a capsid of approximately $22 \mathrm{~nm}$, and one of the most frequent members of the family. Despite its high prevalence, the virus has not been associated to any human illness. Since a co-infecting helper virus is required for productive infection, adeno-associated viruses are ascribed to a separate genus (Dependovirus) in the Parvoviridae family. Numerous serotypes of AAV have been identified, but the majority of rAAV vectors are based on AAV serotype 2 (AAV2).

The wild AAV2 life cycle in human cells consists first in its binding to a serotype-specific receptor/coreceptor at the cell surface followed by its entry into the cell through endocytosis. Thereafter, the virus needs to escape from the endosome, uncoat and enter the nucleus. In the nucleus, the single-stranded (ss) viral DNA needs to be converted into double-stranded (ds) replicative intermediates, from which regulatory and structural viral proteins are transcribed, as well as the ssDNA for packaging into the new viral particles. This conversion is probably carried out by

Table 3 - Main viral vector systems.

\begin{tabular}{|c|c|c|c|c|}
\hline Viral vector & Description & Advantages & Limitations & Applications \\
\hline Adenovirus (Ad) & $\begin{array}{l}\text { Icosahedric, } \\
\text { non- enveloped, } \\
\text { genome of } 36 \\
\text { kb, non-integrative }\end{array}$ & $\begin{array}{l}\text { Easy propagation in high } \\
\text { titers, infection of most cell } \\
\text { types; } \\
\text { insertion of large DNA frag- } \\
\text { ments }\end{array}$ & $\begin{array}{l}\text { High immunogenicity, in- } \\
\text { ducing important cellular and } \\
\text { humoral immune responses } \\
\text { that can be fatal }\end{array}$ & $\begin{array}{l}\text { Therapies that require tran- } \\
\text { sient gene expression: cancer } \\
\text { therapy, angiogenesis induc- } \\
\text { tion and DNA vaccine pro- } \\
\text { duction (due to its inflamma- } \\
\text { tory and immunogenic } \\
\text { properties) }\end{array}$ \\
\hline $\begin{array}{l}\text { Retroviruses (Retrovirus } \\
\text { and Lentivirus) }\end{array}$ & $\begin{array}{l}\text { Integrative in proliferative } \\
\text { (retrovirus and lentivirus) } \\
\text { and quiescent (lentivirus) } \\
\text { cells }\end{array}$ & $\begin{array}{l}\text { Low immunogenicity, possi- } \\
\text { bility of insertion of large } \\
\text { DNA fragments (up to } 8 \mathrm{~kb} \text { ) }\end{array}$ & Insertional mutagenesis & $\begin{array}{l}\text { Genetic diseases of T cells } \\
\text { and hematological diseases } \\
\text { (Retrovirus), } \\
\text { HIV/AIDS }\end{array}$ \\
\hline $\begin{array}{l}\text { Adeno-associated virus } \\
\text { (AAV) }\end{array}$ & $\begin{array}{l}\text { Icosahedric, } \\
\text { non- enveloped, } \\
\text { single-stranded DNA, } \\
\text { genome of } 4.7 \mathrm{~kb} \text {, } \\
\text { integrative }\end{array}$ & $\begin{array}{l}\text { Low immunogenicity, } \\
\text { easy propagation in high } \\
\text { titers, infection of most of } \\
\text { cell types, long-term gene } \\
\text { expression }\end{array}$ & $\begin{array}{l}\text { Limited capacity for inser- } \\
\text { tion of DNA fragments }\end{array}$ & $\begin{array}{l}\text { Genetic diseases, tumors, } \\
\text { neurological, ocular and car- } \\
\text { diovascular diseases, others }\end{array}$ \\
\hline
\end{tabular}


some not yet identified cellular DNA repair mechanism (reviewed in Stender et al., 2007). These dsDNA intermediates integrate into a specific site of human chromosome 19 (19q13.3q-ter) called AAVS1 (Kotin et al., 1990; Kotin et al., 1991; Samulski et al., 1991; McCarty et al., 2004; Philpott et al., 2004; Wang and Lieber, 2006). In the absence of a co-infection by a helper virus (commonly adenovirus or herpesvirus), the integrated AAV genome remains in a latent state. When the host cell is co-infected by a helper virus, the changes of the cellular milieu lead to the activation of the integrated AAV dsDNA that initiates the transcription of the regulatory and structural viral genes, as well as the replication of viral DNA, generating the ssDNA to be packaged into novel viral particles. The viral DNA replication process relies on host cell polymerase activities, since AAV does not encode a proper polymerase (Ni et al., 1998). Although the encapsidation process is still not well understood, there is evidence that it is a nuclear process (Wistuba et al., 1997). This evidence also indicate that there are specific patterns of distribution and transport of viral proteins between cellular compartments in each stage of a productive infection. Capsid assembly probably occurs in the nucleolus and is then relocalized into the nucleoplasm, with some influence of Rep proteins. The colocalization of the empty assembled capsid, the Rep proteins and the ssDNA AAV genome in the nucleoplasm allows the encapsidation process to occur (Im and Muzyczka, 1989; Wistuba et al., 1997; King et al., 2001; Bleker et al., 2005). Finally, the novel viral particles exit the cell, probably by an unknown exocytosis mechanism.

The wild AAV has a linear single-stranded DNA genome of approximately $4.7 \mathrm{~kb}$ of either plus or minus polarity. The AAV DNA ends are constituted of a $145 \mathrm{bp}$ inverted terminal repeat (ITR), whose terminal 125 bases are multipalindromic, leading to a characteristic T-shaped hairpin structure (Koczot et al., 1973). This structure becomes a 3' hydroxyl group available as a primer for the initiation of viral DNA replication (Berns, 1990).

The ITRs that act as DNA replication origin, packaging and integration signal, also act as a regulator element for wild AAV gene expression. Two viral genes located between the ITRs, rep and cap, encode proteins involved in viral replication and capsid formation, respectively (Figure 1A). The rep gene encodes four regulatory proteins called Rep78, Rep68, Rep52 and Rep40, according to their molecular weight. This is possible due to the use of two alternative promoters ( $\mathrm{p} 5$ and $\mathrm{p} 19)$ and an internal splice donor and acceptor site.

Rep78 and Rep68 are site-specific DNA binding proteins that interact with specific sites within the ITRs (Repbinding element - RBE - and terminal resolution site - trs), playing a crucial role in DNA replication, transcriptional control and site-specific integration processes. They also act as positive or negative regulators of AAV gene expression, depending on the presence or absence of a helper vi-

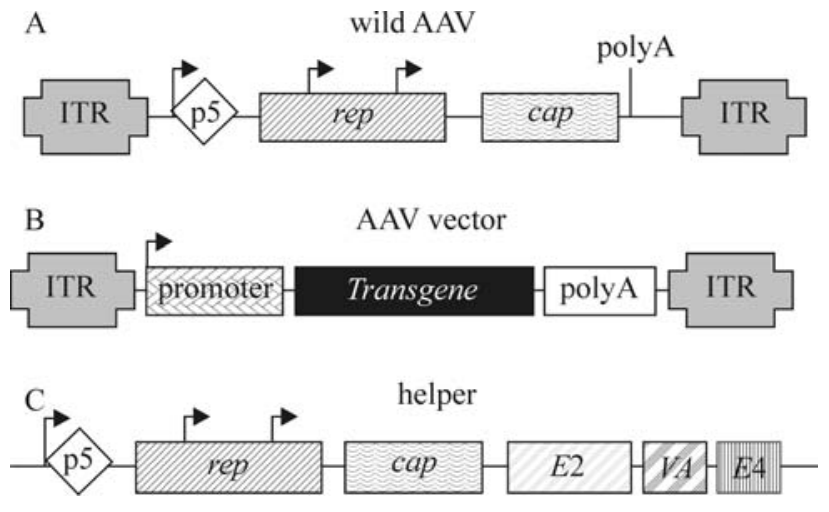

Figure 1 - AAV genetic structure. (A) Wild AAV; (B) AAV vector cassette, containing only the ITRs of the wild virus and the transgene and its promoter; $(C)$ helper cassette, containing the AAV rep and cap genes required for virus packaging and the Ad genes E2, VA and E4, required for virus replication (adapted from Pfeifer and Verma, 2001).

rus, respectively (Pereira et al., 1997). Moreover, these proteins have endonuclease (Berns and Giraud, 1996), helicase and ATPase (Im and Muzyczka, 1990) activities.

The Rep52 and Rep40 proteins participate in the generation and accumulation of the plus and minus ssDNA viral genome from the dsDNA intermediates (Chejanovsky and Carter, 1989). The single-stranded genomes of both polarities are packaged with equal efficiency (Berns and Adler, 1972). Similar to Rep78 and Rep68, these proteins also exhibit helicase and ATPase activities (Smith and Kotin, 1998; Collaco et al., 2003).

The cap gene has a single promoter (p40) that transcribes two messenger RNAs (mRNA) through alternative splicing at two acceptor sites. The larger mRNA encodes the virion protein 1 (VP1), the largest protein subunit of the capsid ( $\sim 87 \mathrm{kDa})$. The shorter transcript presents a conventional initiation codon (AUG), which originates the VP3 capsid protein $(\sim 62 \mathrm{kDa})$, and an upstream non-canonical start codon (ACG) that generates VP2 ( $72 \mathrm{kDa})$. These three capsid proteins differ among them at the $\mathrm{N}$ terminus. VP1, VP2 and VP3 assemble in a molar ratio of 1:1:10, respectively, forming a near-spherical protein shell of 60 subunits that leads to perfect icosahedral symmetry (Bleker $e t$ al., 2005). A conserved phospholipase $\mathrm{A}_{2}$ (PLA2) motif, located within the VP1 N-terminal region (Zádori et al., 2001), was reported to have a biological significance in AAV2 infection (Girod et al., 2002). It seems to play a crucial role in the trafficking of the AAV genome from the endosome to the nucleus and in the initiation of viral gene expression (Girod et al., 2002; Bleker et al., 2005).

\section{Adeno-associated virus biology and trafficking in host cells}

As mentioned above, AAV infection is initiated by binding to cell surface receptors that are serotype-specific. AAV2, for instance, has the heparan sulfate proteoglycan (HSPG) as one of its primary attachment receptors (Sum- 
merford and Samulski, 1998). The binding to a receptor is not a sufficient stimulus for viral internalization, which, additionally, requires binding to co-receptors, such as $\alpha_{v} \beta_{5}$ integrin heterodimers (Summerford et al., 1999), fibroblast growth factor receptor type 1 (Qing et al., 1999) and the hepatocyte growth factor receptor, c-Met (Kashiwakura et al., 2005). HSPG is ubiquitously distributed in cells and tissues of several species. This can explain in part the broad tropism of this virus that includes human, non-human primate, canine, murine and avian cell types. $\mathrm{N}$ - and O-linked sialic acids act as receptors for AAV5 and AAV4, respectively (Kaludov et al., 2001). The platelet-derived growth factor receptor has been identified as another cellular determinant involved in AAV5 infection (Di Pasquale et al., 2003).

Different AAV serotypes preferentially transduce different cell types (Burger et al., 2004). In general, the tropism is associated with abundance of the specific receptor/coreceptor, but there are exceptions (Duan et al., 1999; Duan et al., 2000), suggesting that probably there are other internalization pathways independent of known receptors (Ding et al., 2005).

The events that control rAAV transduction following receptor binding and leading to nuclear uptake have been found to be a major rate-limiting step in rAAV transduction for many cell types. Some studies in this area have also suggested that the rate of intracellular processing and the process of uncoating of viral vectors may critically affect host immune responses toward input capsids, in the absence of new viral protein synthesis (Campbell and Hope, 2005; Ding et al., 2005).

The current knowledge of AAV trafficking is based on a limited number of serotypes, particularly AAV2 and AAV5, and there are relatively few reports about intracellular trafficking for any of the other AAV serotypes. The knowledge of the intracellular processing in these and other existing serotypes is becoming even more important with the increasing identification of new AAV serotypes (Campbell and Hope, 2005; Ding et al., 2005).

Although current advances in technology have greatly increased our ability to dissect the complexities of AAV intracellular trafficking, the events and processes that regulate the trafficking of AAV particles into the nucleus are still not fully understood. In vitro experiments have indicated that one of the routes this virus can use to get through the plasma membrane involves receptor-mediated endocytosis, via the formation of clathrin-coated pits (Duan et al., 1999; Bartlett et al., 2000). Other studies have suggested that internalized virions escape from endosomes and are released in the cytosol by a low $\mathrm{pH}$-dependent process (Bartlett et al., 2000). In addition, experiments employing a powerful new imaging technique that enables real-time monitoring of the trajectories of individual virions (Seisenberger et al., 2001) have shown that each endosome carries a single AAV particle. There are reports that support the in- volvement of microtubule assembly and motor proteins in active AAV intracellular transport. It has also been suggested that AAV particles can access the nucleus through the nuclear pore complex (NPC) due to their very small size. However, recent research points to a nuclear entry process that is not dependent on NPC activity (Hansen et al., 2001; Xiao et al., 2002), whereas the issue of whether AAV capsids enter nuclei intact or remodeled seems to depend on the presence or absence, respectively, of co-infecting helper Ad particles (Xiao et al., 2002).

After reaching the nucleus, the wild-type AAV2 is able to integrate into the host genome in dividing cells and, at a lesser frequency, also in non-dividing cells. This integration occurs preferentially into a specific site of the $\mathrm{q}$ arm of chromosome 19 (AAVS1) in a Rep-dependent manner (Kotin et al., 1990; Kotin et al., 1991; Samulski et al., 1991; McCarty et al., 2004; Philpott et al., 2004; Wang and Lieber, 2006). Specific integration sites for the other AAV serotypes have not yet been identified.

\section{Adeno-associated virus serotypes}

Human AAV was discovered as a contaminant of adenovirus (Ad) preparations in 1965 (Atchison et al., 1965). After the establishment of the first infectious clone of AAV2 in 1982 (Samulski et al., 1982), it has rapidly gained popularity in gene therapy applications, due to characteristics such as lack of pathogenicity, wide range of infectivity, and ability to establish long-term transgene expression.

Up to date, several AAV serotypes and over 100 AAV new isolates have been acquired from adenovirus stocks or from human/nonhuman primate tissues (Atchison et al., 1965; Hoggan et al., 1966; Parks et al., 1967; Bantel-Schaal and zur Hausen, 1984; Rutledge et al., 1998; Gao et al., 2002; Gao et al., 2004; Mori et al., 2004; Schmidt et al., 2006). The over 100 new AAV isolates are called AAV variants since their serology is not currently available. Alternative AAV serotypes can result in lower vector load requirements due to their potentially higher transduction efficiency. They also help to evade preexisting neutralizing antibodies generated as a result of humoral immune responses to natural infection. Moreover, as more serotypes are characterized and the capsids of the different serotypes are combined to obtain new tropisms, it will be possible that tissues not easily infected by known AAV serotypes become susceptible to gene transfer based on this vector, expanding and complementing the current range of AAV-based vectors.

By definition, a new serotype is a newly isolated virus that does not efficiently cross-react with neutralizing sera specific for all other existing and characterized serotypes. In this way, only AAV1 to AAV5 and AAV7 to AAV9 can be defined as real serotypes. Variants AAV6, AAV10 and AAV11 do not appear to fit into this definition, since the serology of AAV6 is similar to that of AAV1 (Gao et al., 
2002; Grimm and Kay, 2003; Gao et al., 2004), and serological profiles of AAV10 and AAV11 are not well characterized yet (Mori et al., 2004).

There is evidence that the in vivo transduction efficiency of one AAV vector serotype is generally unaffected by preexisting neutralizing antibodies to another serotype (Xiao et al., 1999; Halbert et al., 2000; Peden et al., 2004). However, there are also reports that indicate that the extent of AAV serotype cross-reactivity could be species-specific or dependent on target tissue and route of administration (Wu et al., 2006).

With exemption of AAV5, which was isolated from a human penile condylomatous wart (Bantel-Schaal and Hausen, 1984), AAV serotypes 1 to 6 were isolated as contaminants in laboratory adenovirus stocks. Since there is a relatively high prevalence of neutralizing antibodies in human populations against AAV2, AAV3 and AAV5, these serotypes are thought to be of human origin (Blacklow et al., 1968; Parks et al., 1970; Georg-Fries et al., 1984; Erles et al., 1999). In contrast, AAV4 is thought to originate from monkey samples since antibodies against it are common in nonhuman primates (Parks et al., 1970). Antibodies to AAV1 were found in monkey sera (Parks et al., 1970), whereas AAV1 viral genomes have been isolated from human tissues (Gao et al., 2004). Therefore, it still remains an open question whether AAV1 originated from humans or from nonhuman primates.

AAV6 is thought to be a hybrid recombinant between AAV1 and AAV2, since its left ITR and p5 promoter regions are virtually identical to those of AAV2, while the rest of its genome is nearly identical to that of AAV1 (Rutledge et al., 1998; Xiao et al., 1999). However, it is not clear whether recombination occurred in vivo or in vitro.

In the past 4 years, several novel AAV serotypes, including AAV7, 8 and 9, and over 100 AAV variants have been found in human or nonhuman primate tissues (Gao et al., 2002; Gao et al., 2004; Mori et al., 2004; Schmidt et al., 2006; Gao et al., 2005). Different from AAV1 to 6, the new $\mathrm{AAV}$ serotypes and variants were not isolated as live virus forms; instead, they were isolated as DNA sequences using a specific PCR-based strategy (Gao et al., 2004; Gao et al., 2005).

AAV genomes have not been isolated only from primates, but also from other species such as horse (Dutta, 1975), lizard (Jacobson et al., 1996), chicken (Bossis and Chiorini, 2003), cow (Schmidt et al., 2004), snake (Farkas et al., 2004) and goat (Olson et al., 2004; Arbetman et al., 2005). Among these, AAV isolates from bovine, avian and caprine species have been developed into vectors for gene transfer studies (Schmidt et al., 2004; Bossis and Chiorini, 2003; Arbetman et al., 2005).

These AAV serotypes share a common genome structure, but show variation in cell and tissue tropism due to differences in their capsid proteins that lead to recognition by different cell surface receptors. The more commonly used serotype for vector production is still AAV2 which exceedingly infects the brain, retina and kidney, and is being widely used in applications involving these organs. AAV1 and AAV7 show a major tropism for skeletal muscle. AAV4 and AAV5 appear to have a stronger tropism for the central nervous system and photoreceptor cells. Finally, AAV8 shows greater tropism for heart, pancreas, liver and muscle; and AAV9, for lung, muscle and liver (Ding et al., 2005; reviewed in Wu et al., 2006).

\section{AAV-based recombinant vectors}

All AAV-based vectors are derived from a plasmid that has only the AAV $145 \mathrm{bp}$ inverted terminal repeats (ITRs) flanking the cassette with the transgene of choice. Since all required cis functions for vector production are located in the ITR region and in the immediately adjacent 45 nucleotides, the two open reading frames (ORFs), rep and cap, can be completely replaced by the transgene of interest and its promoter (Figure 1B). Vectors with up to $5.2 \mathrm{~kb}$ size can be packaged, although the optimal size for the AAV vector genome is between 4.1 and $4.9 \mathrm{~kb}$. The rep and cap genes are provided in another plasmid, the package plasmid (Tal, 2000; Pfeifer and Verma, 2001). Acquisition of rAAV used to require the transfection of both constructs in Ad infected cells (Pfeifer and Verma, 2001). Since there is no homology between vector and helper sequences, rAAVs produced in this system are essentially free from wild AAV. This minimizes the possibility of undesirable gene expression that causes host immune responses, as observed for other vectors. In addition to AAV capacity to infect both mitotic and post-mitotic cells, recent in vivo studies are resulting in efficient and persistent gene transfer to several tissues, organs and systems, including the central nervous system, retina, muscle, lung and liver (reviewed in Xiao and Samulski, 1998; Tal, 2000; Pfeifer and Verma, 2001).

Although wild AAV is able to integrate into the host genome in a specific site on chromosome 19, this sitespecific integration requires the viral protein Rep that is normally absent in current AAV vectors (Kotin et al., 1990; Linden et al., 1996). Therefore, common AAV vectors usually remain within the target tissues as episomal entities (90\%), although they can also integrate into the host cell's genome (10\%) (Goverdhana et al., 2005). The extent to which recombinant genomes are able to integrate in the absence of Rep functions is still in discussion. Recently, the preferential integration of AAV2 vectors in transcriptionally active chromatin regions in hepatocytes has been demonstrated (Nakai et al., 2003; Russell, 2003). Whether this is a general phenomenon, or specific for liver or AAV2, has to be further investigated. Although usually remaining in an episomal form, AAV vectors can lead to long-term transgene expression in comparison to other vectors. However, the development of a superior class of AAV-based vectors is required to ensure host genome integration. 
Although involved in wild AAV gene expression, ITR sequences are excluded from the helper plasmid to avoid generation of recombinant wild AAV. The AAV promoter region $\mathrm{p} 5$ also acts as an enhancer in the regulation of expression of proteins p19 and p40, Rep52/42 and Cap. Therefore, gene expression of packaged plasmid should be optimized for Rep and Cap expression in order to achieve efficient vector replication and packaging. Overexpression of AAV Rep 78/68 by the replacement of $\mathrm{p} 5$ promoter with strong heterologous promoters results in a considerably lower rAAV production. On the other hand, Rep 78/68 underexpression, through replacement of the initiation codon ATG by ACG and addition of a second copy of the p5 promoter 3' from Cap, inhibiting its own transcriptional activity, results in higher rAAV production (approximately 15 fold more than by conventional package plasmids). This suggests that proper regulation of AAV gene expression has a crucial role in rAAV production, and that the handling of the package plasmid to optimize gene expression can lead to an improvement in vector production. Moreover, the proper supply of helper functions from Ad essential genes is also crucial, since these genes regulate AAV gene expression and also modify the cellular microenvironment to allow AAV spreading (Tal, 2000; Pfeifer and Verma, 2001; Smith, 2003).

As mentioned previously, a remarkable characteristic of AAV is the requirement of co-infection with a nonrelated virus, such as Ad, to supply essential helper functions for a productive viral cycle. Several adenoviral genes, including E1a,E1b, E2a,E4 and VA RNA have these helper functions. $E 1 a$ acts as a transactivator, overregulating the transcriptional activity of various Ad genes, as well as $\mathrm{AAV}$ rep and cap genes. The $E 1 b$ gene interacts with $E 4$ facilitating viral mRNA transport in the appropriate moment. The $E 4$ gene, especially ORF 6 , is also involved in the facilitation of AAV DNA replication. E2a and VA RNA genes increase the stability and efficacy of AAV mRNA translation, especially for Cap gene transcripts (Pfeifer and Verma, 2001).

Although this is the most efficient procedure to introduce Ad helper genes, several problems arise as a result of Ad infection. The first is the requirement to remove contaminating Ad particles. Moreover, the inherent competition between AAV and Ad for critical viral gene functions affects the final vector production. The complete removal of $\mathrm{Ad}$ is based on physical techniques that include $\mathrm{CsCl}_{2}$, chromatography and a step of heat denaturation in order to inactivate any Ad residual particles (Vincent et al., 1997). Although the majority of these procedures is well succeeded to a certain level, potential Ad contamination is still an undesirable risk and the presence of denatured Ad proteins is unacceptable for clinical purposes. Therefore, the possibility of producing rAAV in the absence of Ad, as described by Xiao and Samulski (1998), through a system of three plasmids, a rAAV vector plasmid, a package plasmid (with rep and cap genes) and a helper plasmid (containing only the Ad5 genes E2a,E4 and VA RNA), constitutes a promising alternative for the potentialization of AAV vectors in gene therapy. More recently, efficient systems with only two plasmids - a rAAV vector plasmid and the helper containing the $\mathrm{AAV}$ and $\mathrm{Ad}$ genes required for package and replication - have been described (Zolotukhin et al., 2002) (Figure 1C). In all cases, the cell packaging line used is HEK293, whose genome contains the Ad E1 gene (Figure 2).

Despite the currently great number of available recombinant AAV (rAAV) serotypes and variants, several biological barriers appear to limit the effectiveness of rAAVs for gene therapy. Understanding the fundamental basis of these barriers has aided in establishing methods to improve the efficiency of rAAV-mediated gene delivery. These biological barriers are inherent to the AAV life cycle and to its infectious process, as already described above (Figure 3) (Ding et al., 2005). Each intracellular stage required for successful AAV infection constitutes a barrier for rAAV cell transduction. AAV entry pathways probably determine the routes by which the virus crosses the cell cytoplasm to enter into the nucleus. Consequently, viral receptors and coreceptors involved in endocytosis and movement of AAV through the endosomal compartment should be the focus of intracellular trafficking studies.

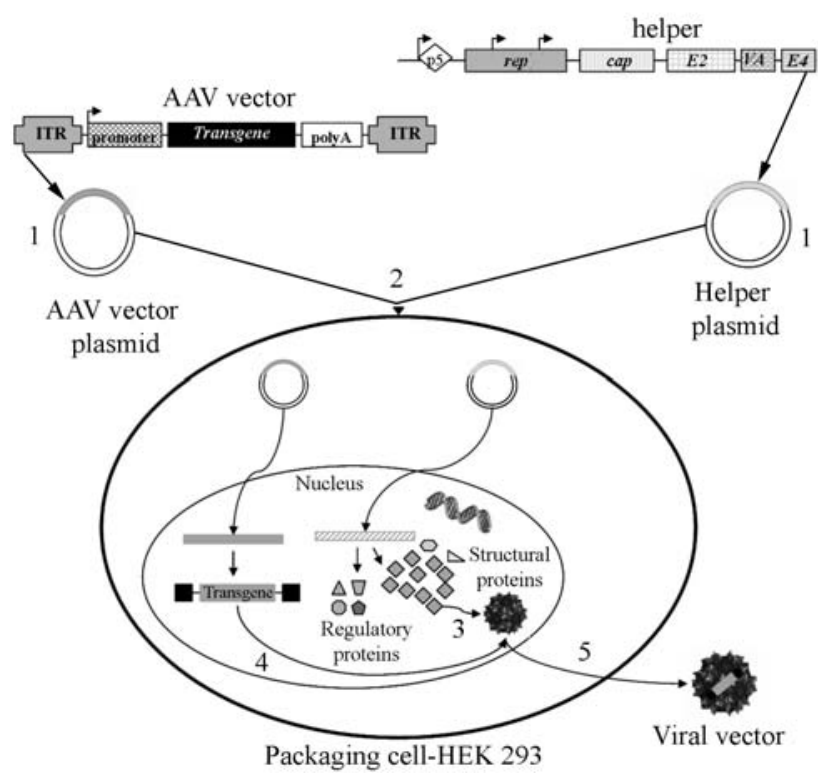

Figure 2 - AAV recombinant vector production. Insertion of the AAV vector and helper cassettes into the respective plasmids (1); co-transfection of both plasmids in HEK 293 packaging cells, whose genome contains the Ad E1 gene, which together with the other Ad required genes, supplied by the helper plasmid, allows the establishment of a productive infection (2); empty capsid is formed by AAV structural proteins assembly into the nucleolus (3); the replicated ssDNA viral genome with the transgene flanked by ITRs (vector plasmid) are packaged into the empty capsid in the nucleoplasm (4), giving rise to a non-replicative recombinant $A A V$ vector virion (5). The regulatory proteins act especially in the replication and packaging processes. 


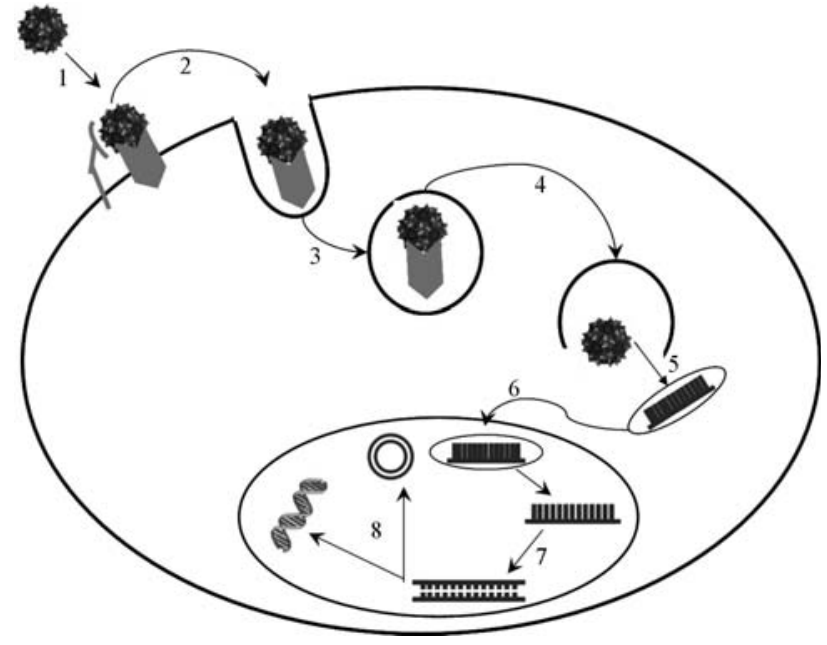

Figure 3 - Course of AAV productive infection. Scheme showing the eight steps of AAV transduction of host cells: (1) viral binding to a membrane receptor/coreceptor; (2) endocytosis of the virus by the host cell; (3) virus intracellular trafficking through the endosomal compartment; (4) escape of the virus from the endosome; (5) virion uncoating; (6) entry into the nucleus; (7) viral genome conversion from a single-stranded to a double-stranded genome; and (8) integration into the host genome or permanence of an episomal form capable of expressing an encoded gene (adapted from Ding et al., 2005).

\section{AAV-based vectors gene therapy applications}

The establishment of the first infectious clone of AAV serotype 2 (AAV2) in 1982 (Samulski et al., 1982) and the pioneering work on the successful cloning of AAV, also in the early 1980s, laid the foundation of recombinant $\mathrm{AAV}$ vectors capable of expressing foreign genes in mammalian cells (Laughlin et al., 1983; Hermonat and Muzyczka, 1984). Since then AAV2 vectors have rapidly gained popularity in gene therapy applications, due to their unique and desirable biological features (reviewed by Coura and Nardi, 2007). This class of viruses has adapted to coexist with mammalian hosts in a manner that allows for long-term persistence without any detectable deleterious effect on the host. Despite the deceptively simple structure of $\mathrm{AAV}$, this virus is able to use its nonstructural proteins to facilitate replication as a satellite of other DNA viruses during its productive phase, as well as to establish stable integrated and episomal forms during its latent phase (Berns et al., 1975; Berns, 1990; Berns and Linden, 1995). Therefore, the nonpathogenic and persistent long-term nature of AAV infection combined with its wide range of infectivity has made this virus an important candidate as a therapeutic gene transfer vector.

Recombinant adeno-associated viral (rAAV) vectors have rapidly advanced to the forefront of gene therapy in the past decade, since they have been successfully overcoming gene therapy challenges such as transgene maintenance, security, host immune response and target diseases, and meeting the desirable vector system features of high level of safety combined with clinical efficacy and versatil- ity in terms of potential applications. Consequently, despite the already existing limitations and concerns to be resolved, rAAV are increasingly becoming the vectors of choice for a wide range of gene therapy approaches.

Until recently, the better studied and the most frequently used AAV serotype for gene therapy was AAV2. Other new serotypes, however, are gaining more and more popularity. Recombinant AAV2 vectors have been tested in preclinical studies for a variety of diseases such as genetic diseases (hemophilia, $\mu 1$-anti-trypsin deficiency, cystic fibrosis, Duchenne muscular dystrophy and others) (Hildinger and Auricchio, 2004), tumors (Ng et al., 2007), neurological disorders (Paterna et al., 2007), ocular (Martin et al., 2002; Smith et al., 2005) and cardiovascular diseases (Jazwa et al., 2007; Liu et al., 2006; Shenouda et al., 2006), chronic disorders (Ideno et al., 2007; Blenman et al., 2006; Sandalon et al., 2007) and others.

Several clinical trials have already been performed for various diseases, especially monogenic diseases and tumors. Currently, there are more than 20 open clinical trials evaluating the use of AAV vectors for genetic and acquired diseases (Pfeifer and Verma, 2001; Worgall, 2005; Clinical trial database - http://www.wiley.com.uk/genetherapy/ clinical/).

\section{Future directions}

Since its isolation, the biological properties of the adeno-associated virus have been increasingly understood, improving our ability to manipulate and use it as a safe and efficient gene therapy vector of wide spectrum. AAVbased vectors seem to bypass the main gene therapy barriers, such as long-term and stable transgene expression in many tissues, safety, broad range of target diseases and lack of immunogenicity and pathogenicity. However, although some obstacles have already been overcome, others are rising and need to be surpassed now, and research advances will certainly bring more challenges in the near future.

\section{Acknowledgments}

This work was supported by Conselho Nacional de Desenvolvimento Científico e Tecnológico (CNPq), through the program Instituto do Milênio - Rede de Terapia Gênica.

\section{References}

Arbetman AE, Lochrie M, Zhou S, Wellman J, Scallan C, Doroudchi MM, Radley B, Patarroyo-White S, Liu T, Smith P et al. (2005) Novel caprine adeno-associated virus (AAV) capsid (AAVGo1) is closely related to the primate AAV-5 and has unique tropism and neutralization properties. J Virol 79:15238-15245.

Atchison RW, Casto BC and Hammon M (1965) Adenovirusassociated defective virus particles. Science 149:754-756. 
Bantel-Schaal U and zur Hausen H (1984) Characterization of the DNA of a defective human parvovirus isolated from a genital site. Virology 134:52-63.

Bartlett JS, Wilcher R and Samulski RJ (2000) Infectious entry pathway of adeno-associated virus and adeno-associated virus vectors. J Virol 74:2777-2785.

Berns KI, Pinkerton TC, Thomas GF and Hoggan MD (1975) Detection of adeno-associated virus (AAV)-specific nucleotide sequences in DNA isolated from latently infected Detroit 6 cells. Virology 68:556-560.

Berns K (1990) Parvovirus replication. Microbiol Rev 54:316329.

Berns KI and Adler S (1972) Separation of two types of adenoassociated virus particles containing complementary polynucleotide chains. J Virol 9:394-396.

Berns KI and Linden RM (1995) The cryptic life style of adenoassociated virus. Bioessays 17:237-245.

Berns KI and Giraud C (1996) Biology of adeno-associated virus. Curr Top Microbiol Immunol 218:1-23.

Blacklow NR, Hoggan MD and Rowe WP (1968) Serologic evidence for human infection with adenovirus-associated viruses. J Natl Cancer Inst 40:319-327.

Blaese RM, Culver KC, Miller AD, Carter CS, Fleisher T, Sheare G, Chang L, Chiang Y, Tolstoshev P, Greenblatt JJ et al. (1995) T lymphocyte-directed gene therapy for ADASCID: Initial trial results after 4 years. Science 270:475-480.

Bleker S, Sonntag F and Kleinschmidt JA (2005) Mutational analysis of narrow pores at the fivefold symmetry axes of adeno-associated virus type 2 capsids reveals a dual role in genome packaging and activation of phospholipase A2 activity. J Virol 79:2528-2540.

Blenman KR, Duan B, Xu Z, Wan S, Atkinson MA, Flotte TR, Croker BP and Morel L (2006) IL-10 regulation of lupus in the NZM2410 murine model. Lab Invest 86:1136-1148.

Bossis I and Chiorini JA (2003) Cloning of an avian adenoassociated virus (AAV) and generation of recombinant AAV particles. J Virol 77:6799-6810.

Burger C, Gorbatyuk OS, Velardo MJ, Peden CS, Williams P, Zolotukhin S, Reier PJ, Mandel RJ and Muzyczka N (2004) Recombinant AAV viral vectors pseudotyped with viral capsids from serotypes 1,2 , and 5 display differential efficiency and cell tropism after delivery to different regions of the central nervous system. Mol Ther 10:302-317.

Campbell EM and Hope TJ (2005) Gene therapy progress and prospects: Viral trafficking during infection. Gene Ther 12:1353-1359.

Chejanovsky N and Carter BJ (1989) Mutagenesis of an AUG codon in the adeno-associated virus rep gene: Effects on viral DNA replication. Virology 173:120-128.

Collaco RF, Kalman-Maltese V, Smith AD, Dignam JD and Trempe JP (2003) A biochemical characterization of the adeno-associated virus rep40 helicase. J Biol Chem 278:34011-34017.

Coura RD and Nardi NB (2007) The state of the art of adenoassociated virus-based vectors in gene therapy. Virol J 4:99.

Di Pasquale G, Davidson BL, Stein CS, Martins I, Scudiero D, Monks A and Chiorini JA (2003) Identification of PDGFR as a receptor for AAV-5 transduction. Nat Med 9:13061312 .
Ding W, Zhang L, Yan Z and Engelhardt JF (2005) Intracellular trafficking of adeno-associated viral vectors. Gene Ther 12:873-880

Duan D, Li Q, Kao AW, Yue Y, Pessin JE and Engelhardt JF (1999) Dynamin is required for recombinant adenoassociated virus type 2 infection. J Virol 73:10371-10376.

Duan D, Yue Y, Yan Z, Yang J and Engelhardt JF (2000) Endosomal processing limits gene transfer to polarized airway epithelia by adeno-associated virus. J Clin Invest 105:15731587.

Dutta SK (1975) Isolation and characterization of an adenovirus and isolation of its adenovirus-associated virus in cell culture from foals with respiratory tract disease. Am J Vet Res $36: 247-250$

Edelstein ML, Abedi MR, Wixon J and Edelstein RM (2004) Gene therapy clinical trials worldwide 1989-2004-an overview. J Gene Med 6:597-602.

El-Aneed A (2004) Current strategies in cancer gene therapy. Eur J Pharmacol 498:1-8.

Erles K, Sebokova P and Schlehofer JR (1999) Update on the prevalence of serum antibodies (IgG and $\operatorname{IgM}$ ) to adenoassociated virus (AAV). J Med Virol 59:406-411.

Farkas SL, Zadori Z, Benko M, Essbauer S, Harrach B and Tijssen P (2004) A parvovirus isolated from royal python (Python regius) is a member of the genus Dependovirus. J Gen Virol $85: 555-561$

Gao G, Alvira MR, Wang L, Calcedo R, Johnston J and Wilson JM (2002) Novel adeno-associated viruses from rhesus monkeys as vectors for human gene therapy. Proc Natl Acad Sci USA 99:11854-11859.

Gao G, Vandenberghe LH, Alvira MR, Lu Y, Calcedo R, Zhou X and Wilson JM (2004) Clades of adeno-associated viruses are widely disseminated in human tissues. J Virol 78:63816388.

Gao G, Vandenberghe LH and Wilson JM (2005) New recombinant serotypes of AAV vectors. Curr Gene Ther 5:285-297.

Gao X, Kim K-S and Liu D (2007) Nonviral gene delivery: What we know and what is next. AAPS J 9:E92-E104.

Georg-Fries B, Biederlack S, Wolf J and zur Hausen H (1984) Analysis of proteins, helper dependence, and seroepidemiology of a new human parvovirus. Virology 134:64-71.

Girod A, Wobus CE, Zádori Z, Ried M, Leike K, Tijssen P, Kleinschmidt JA and Hallek M (2002) The VP1 capsid protein of adeno-associated virus type 2 is carrying a phospholipase A2 domain required for virus infectivity. J Gen Virol 83:973-978

Goverdhana S, Puntel M, Xiong W, Zirger JM, Barcia C, Curtin JF, Soffer EB, Mondkar S, King GD, Hu J et al. (2005) Regulatable gene expression systems for gene therapy applications: Progress and future challenges. Mol Ther 12:189211.

Grimm D and Kay MA (2003) From virus evolution to vector revolution: Use of naturally occurring serotypes of adenoassociated virus (AAV) as novel vectors for human gene therapy. Curr Gene Ther 3:281-304.

Halbert CL, Rutledge EA, Allen JM, Russell DW and Miller AD (2000) Repeat transduction in the mouse lung by using adeno-associated virus vectors with different serotypes. J Virol 74:1524-1532.

Hansen J, Qing K and Srivastava A (2001) Adeno-associated virus type 2-mediated gene transfer: Altered endocytic pro- 
cessing enhances transduction efficiency in murine fibroblasts. J Virol 75:4080-4090.

Hermonat PL and Muzyczka N (1984) Use of adeno-associated virus as a mammalian DNA cloning vector: Transduction of neomycin resistance into mammalian tissue cultured cells. Proc Natl Acad Sci USA 81:6466-6470.

Hildinger M and Auricchio A (2004) Advances in AAV-mediated gene transfer for the treatment of inherited disorders. Eur J Hum Genet 12:263-271.

Hoggan MD, Blacklow NR and Rowe WP (1966) Studies of small DNA viruses found in various adenovirus preparations: Physical, biological and immunological characteristics. Proc Natl Acad Sci USA 55:1467-1472.

Ideno J, Mizukami H, Kakehashi A, Saito Y, Okada T, Urabe M, Kume A, Kuroki M, Kawakami M, Ishibashi S et al. (2007) Prevention of diabetic retinopathy by intraocular soluble flt-1 gene transfer in a spontaneously diabetic rat model. Int J Mol Med19:75-79.

Im DS and Muzyczka N (1989) Factors that bind to adenoassociated virus terminal repeats. J Virol 63:3095-3104.

Im DS and Muzyczka N (1990) The AAV origin binding protein Rep68 is an ATP-dependent site-specific endonuclease with DNA helicase activity. Cell 61:447-457.

Jacobson ER, Kopit W, Kennedy FA and Funk RS (1996) Coinfection of a bearded dragon, Pogona vitticeps, with adenovirus- and dependovirus-like viruses. Vet Pathol 33:343346.

Jazwa A, Jozkowicz A and Dulak J (2007) New vectors and strategies for cardiovascular gene therapy. Curr Gene Ther 7:723.

Kaludov N, Brown KE, Walters RW, Zabner J and Chiorini JA (2001) Adeno-associated virus serotype 4 (AAV4) and AAV5 both require sialic acid binding for hemagglutination and efficient transduction but differ in sialic acid linkage specificity. J Virol 75:6884-6893.

Kashiwakura Y, Tamayose K, Iwabuchi K, Hirai Y, Shimada T, Matsumoto K, Nakamura T, Watanabe M, Oshimi K and Daida H (2005) Hepatocyte growth factor receptor is a coreceptor for adeno-associated virus type 2 infection. J Virol 79:609-614.

King JA, Dubielzig R, Grimm D and Kleinschmidt JA (2001) DNA helicasemediated packaging of adeno-associated virus type 2 genomes into preformed capsids. EMBO J 20:32823291.

Koczot FJ, Carter BJ, Garon CF and Rose JA (1973) Selfcomplementarity of terminal sequences within plus or minus strands of adenovirus-associated virus DNA. Proc Natl Acad Sci USA 70:215-219.

Kotin RM, Siniscalco M, Samulski RJ, Zhu XD, Hunter L, Laughlin CA, McLaughlin S, Muzyczka N, Rocchi M and Berns KI (1990) Site-specific integration by adeno-associated virus. Proc Natl Acad Sci USA 87:2211-2215.

Kotin RM, Menninger JC, Ward DC and Berns KI (1991) Mapping and direct visualization of a region-specific viral DNA integration site on chromosome 19q13-qter. Genomics 10:831-834.

Laughlin CA, Tratschin JD, Coon H and Carter BJ (1983) Cloning of infectious adeno-associated virus genomes in bacterial plasmids. Gene 23:65-73.
Linden RM, Ward P, Giraud C, Winocour E and Berns KI (1996) Site-specific integration by adeno-associated virus. Proc Natl Acad Sci USA 93:11288-11294.

Liu Y, Li D, Chen J, Xie J, Bandyopadhyay S, Zhang D, Nemarkommula AR, Liu H, Mehta JL and Hermonat PL (2006) Inhibition of atherogenesis in LDLR knockout mice by systemic delivery of adeno-associated virus type 2-hIL-10. Atherosclerosis 188:19-27.

Martin KR, Klein RL and Quigley HA (2002) Gene delivery to the eye using adeno-associated viral vectors. Methods 28:267275.

McCarty DM, Young Jr SM and Samulski RJ (2004) Integration of adeno-associated virus (AAV) and recombinant AAV vectors. Annu Rev Genet 38:819-845.

Mori S, Wang L, Takeuchi T and Kanda T (2004) Two novel adeno-associated viruses from cynomolgus monkey: Pseudotyping characterization of capsid protein. Virology 330:375-383.

Nakai H, Montini E, Fuess S, Storm TA, Grompe M and Kay MA (2003) AAV serotype 2 vectors preferentially integrate into active genes in mice. Nat Genet 34:297-302.

Ng SS, Gao Y, Chau DH, Li GH, Lai LH, Huang PT, Huang CF, Huang JJ, Chen YC, Kung HF et al. (2007) A novel glioblastoma cancer gene therapy using AAV-mediated longterm expression of human TERT C-terminal polypeptide. Cancer Gene Ther 14:561-572.

Ni T-H, McDonald WF, Zolotukhin I, Melendy T, Waga S, Stillman B and Muzyczka N (1998) Cellular proteins required for adeno-associated virus DNA replication in the absence of adenovirus coinfection. J Virol 72:2777-2787.

Olson EJ, Haskell SR, Frank RK, Lehmkuhl HD, Hobbs LA, Warg JV, Landgraf JG and Wunschmann A (2004) Isolation of an adenovirus and an adeno-associated virus from goat kids with enteritis. J Vet Diagn Invest 16:461-464.

Parks WP, Green M, Pina M and Melnick JL (1967) Physicochemical characterization of adeno-associated satellite virus type 4 and its nucleic acid. J Virol 5:980-987.

Parks WP, Boucger DW, Melnich JL, Taber LH and Yow MD (1970) Seroepidemiological and ecological studies of the adeno-associated satellite viruses. Infect Immun 2:716-722.

Paterna JC, Leng A, Weber E, Feldon J and Büeler H (2007) DJ-1 and Parkin modulate dopamine-dependent behavior and inhibit MPTP-induced nigral dopamine neuron loss in mice. Mol Ther 15:698-704.

Peden CS, Burger C, Muzyczka N and Mandel RJ (2004) Circulating anti-wildtype adeno-associated virus type 2 (AAV2) antibodies inhibit recombinant AAV2 (rAAV2)-mediated, but not rAAV5-mediated, gene transfer in the brain. J Virol 78:6344-6359.

Pereira DJ, McCarty DM and Muzyczka N (1997) The adenoassociated virus (AAV) Rep protein acts as both a repressor and an activator to regulate AAV transcription during a productive infection. J Virol 71:1079-1088.

Pfeifer A and Verma IM (2001) Gene therapy: Promises and problems. Annu Rev Genomics Hum Genet 2:177-211.

Philpott NJ, Gomos J and Falck-Pedersen E (2004) Transgene expression after rep-mediated site-specific integration into chromosome 19. Hum Gene Ther 15:47-61.

Qing K, Mah C, Hansen J, Zhou S, Dwarki V and Srivastava A (1999) Human fibroblast growth factor receptor 1 is a co- 
receptor for infection by adeno-associated virus 2. Nat Med 5:71-77.

Rosenberg SA, Aebersold P, Cornetta K, Kasid A, Morgan RA, Moen R, Karson EM, Lotze MT, Yang JC and Topalian SL (1990) Gene transfer into humans - Immunotherapy of patients with advanced melanoma, using tumor-infiltrating lymphocytes modified by retroviral gene transduction. $\mathrm{N}$ Engl J Med 323:570-578.

Rubanyi GM (2001) The future of human gene therapy. Mol Aspects Med 22:113-142.

Russell DW (2003) AAV loves an active genome. Nat Genet 34:241-242.

Rutledge EA, Halbert CL and Russell DW (1998) Infectious clones and vectors derived from adeno-associated virus (AAV) serotypes other than AAV type 2. J Virol 72:309319.

Salani B, Damonte P, Zingone A, Barbieri O, Chou JY, D'Costa J, Arya SK, Eva A and Varesio L (2005) Newborn liver gene transfer by an HIV-2-based lentiviral vector. Gene Ther 12:803-814.

Samulski RJ, Berns KI, Tan M and Muzyczka N (1982) Cloning of infectious adeno-associated virus into pBR322: Rescue of intact virus from the recombinant plasmid in human cells. Proc Natl Acad Sci USA 79:2077-2081.

Samulski RJ, Zhu X, Xiao X, Brook JD, Housman DE, Epstein N and Hunter LA (1991) Targeted integration of adenoassociated virus (AAV) into human chromosome 19. EMBO J 10:3941-3950.

Sandalon Z, Bruckheimer EM, Lustig KH and Burstein H (2007) Long-term suppression of experimental arthritis following intramuscular administration of a pseudotyped AAV2/1TNFR:Fc vector. Mol Ther 15:264-269.

Schmidt M, Katano H, Bossis I and Chiorini JA (2004) Cloning and characterization of a bovine adeno-associated virus. $\mathrm{J}$ Virol 78:6509-6516.

Schmidt M, Grot E, Cervenka P, Wainer S, Buck C and Chiorini JA (2006) Identification and characterization of novel adeno-associated virus isolates in ATCC virus stocks. J Virol 80:5082-5085.

Seisenberger G, Ried MU, Endress T, Buning H, Hallek M and Brauchle C (2001) Real-time single-molecule imaging of the infection pathway of an adenoassociated virus. Science 294:1929-1932.

Shenouda SM, Johns C, Kintsurashvili E, Gavras I and Gavras H (2006) Long-term inhibition of the central alpha(2B)-adrenergic receptor gene via recombinant AAV-delivered antisense in hypertensive rats. Am J Hypertens 19:1135-1143.

Smith KR (2003) Gene therapy: Theoretical and bioethical concepts. Arch Med Res 34:247-268.

Smith RH and Kotin RM (1998) The Rep52 gene product of adeno-associated virus is a DNA helicase with 3'-to-5' polarity. J Virol 72:4874-4881.

Smith JR, Verwaerde C, Rolling F, Naud MC, Delanoye A, Thillaye-Goldenberg B, Apparailly F and De Kozak Y (2005) Tetracycline-inducible viral interleukin-10 intraocular gene transfer, using adeno-associated virus in experi- mental autoimmune uveoretinitis. Hum Gene Ther 16:1037-1046.

Stender S, Murphy M, O’Brien T, Stengaard C, Ulrich-Vinther M, Soballe K and Barry F (2007) Adeno-associated viral vector transduction of human mesenchymal stem cells. Eur Cell Mater 13:93-99.

Summerford C and Samulski RJ (1998) Membrane-associated heparan sulfate proteoglycan is a receptor for adeno-associated virus type 2 virions. J Virol 72:1438-1445.

Summerford C, Bartlett JS and Samulski RJ (1999) AlphaVbeta5 integrin: A coreceptors for adeno-associated virus type 2 infection. Nat Med 5:78-82.

Tal J (2000) Adeno-associated virus-based vectors in gene therapy. J Biomed Sci 7:279-291.

Verma IM and Somia N (1997) Gene therapy - Promises, problems and prospects. Nature 389:239-242.

Vincent KA, Piraino ST and Wadsworth SC (1997) Analysis of recombinant adeno-associated virus packaging and requirements for rep and cap gene products. J Virol 71:1897-1905.

Wang H and Lieber A (2006) A helper-dependent capsid-modified adenovirus vector expressing adeno-associated virus rep78 mediates site-specific integration of a 27-kilobase transgene cassette. J Virol 80:11699-11709.

Wiley (2007) Gene Therapy Clinical Trials Worldwide. http:// www.wiley.co.uk/genetherapy/clinical/ (June, 2007).

Wistuba A, Kern A, Weger S, Grimm D and Kleinschmidt J (1997) Subcellular compartmentalization of adenoassociated virus type 2 assembly. J Virol 71:1341-1352.

Worgall S (2005) A realistic chance for gene therapy in the near future. Pediatr Nephrol 20:118-124.

Wu Z, Asokan A and Samulski RJ (2006) Adeno-associated virus serotypes: Vector toolkit for human gene therapy. Mol Ther 14:316-327

Xiao X, Li J and Samulski RJ (1998) Production of high-titer recombinant adenoassociated virus vectors in the absence of helper adenovirus. J Virol 72:2224-2232.

Xiao W, Chirmule N, Berta SC, McCullough B, Gao G and Wilson JM (1999) Gene therapy vectors based on adenoassociated virus type 1. J Virol 73:3994-4003.

Xiao W, Warrington Jr KH, Hearing P, Hughes J and Muzyczka N (2002) Adenovirus-facilitated nuclear translocation of adeno-associated virus type 2. J Virol 76:11505-11517.

Zádori Z, Szelei J, Lacoste M-C, Li Y, Gariépy S, Raymond P, Allaire M, Nabi IR and Tijssen P (2001) A viral phospholipase A2 is required for parvovirus infectivity. Dev Cell 1:291-302.

Zolotukhin S, Potter M, Zolotukhin I, Sakai Y, Loiler S, Fraites TJ Jr, Chiodo VA, Phillipsberg T, Muzyczka N, Hauswirth WW et al. (2002) Production and purification of serotype 1 , 2 , and 5 recombinant adeno-associated viral vectors. Methods 28:158-67.

Zubler RH (2006) Ex vivo expansion of haematopoietic stem cells and gene therapy development. Swiss Med Wkly 136:795799.

Associate Editor: Carlos F.M. Menck 